Research Paper

\title{
Relationship Between People and Urban Places
}

\author{
Ashish KELKAR, The Neo-Urbanism Planners and Designers, India
}

\begin{abstract}
In contemporary urban planning and designing, the places are highly influenced by local cultural values, an image of the city, forming an integral part of the design process. When we travel to different towns and cities, we observe local variation in its socio-economic structure, making the design more vibrant and meaningful to the local culture, e.g., Delhi. The research question covers how efficient, progressive and adaptive the systems are, in a continuously moving timeline and how various actors in the system act in a given situation? The impact is not just restricted to actors as bureaucrats but citizens as well with a strong voice in public participation. Qualitative research methodology is used in this research with inductive reasoning from specific to general, by reviewing of the latest literature in the field. From this literature it is found that how land-use planning systems are making progress with the stakeholders and bureaucrats and people in general with strong public participation and develop planning policies for the future. In conclusion, the solution to the current planning issues lies in the diversity in planning that we enjoy. The local tradition and culture should reflect in the built environment, combined with newly evolved styles and movements in art and architecture.
\end{abstract}

\section{Keywords}

Image of the city, Culture, Planning Policies, Place making, Delhi

\section{Introduction}

Successful Places are those, where people would like to spend their quality time, and have memories associated with it, and would know exactly where they mean. These places often have something unusual, which stands out from places around them, and has a rich character. It is a place where a beautiful and distinctive everchanging vista, with large trees or historic buildings can give voice to the local community and its culture. It is characterised as a well-designed spot, based on its unique local culture, and can make sense of culture as a centre point (Bain, Gray, \& Rodgers, 2012). In contemporary urban planning, these places matter intensely to the human experience of personal activities, interaction, and are conditioned by how far we live and travel daily, alongside our economic prosperity. The specific notion of environmentally sustainable communities is observed in more compact cities and are seen as central to reducing energy consumption. Thus, the secret behind successful places is their impact on socio-economic and environmental sustainability, is something which is essential to understand (Adams, \& Tiesdell, 2012). Such communities promote interpersonal connections and community interactions and are safe, walkable, healthy places, enhancing equitable access to wealth (Cervero, Guerra, \& Al, 2017) and develop into an image of the city. Examples of such urban areas are found all over the world as it is observed in Delhi, the capital of India (Figure 1). Because of its rich history and culture, several architectural monuments of different styles are observed here. Within the historical narrative of the city of Delhi, it covers a period of almost six hundred years in its own unique spatiotemporal dimension (MARLEWICZ, 2016, 162p). 


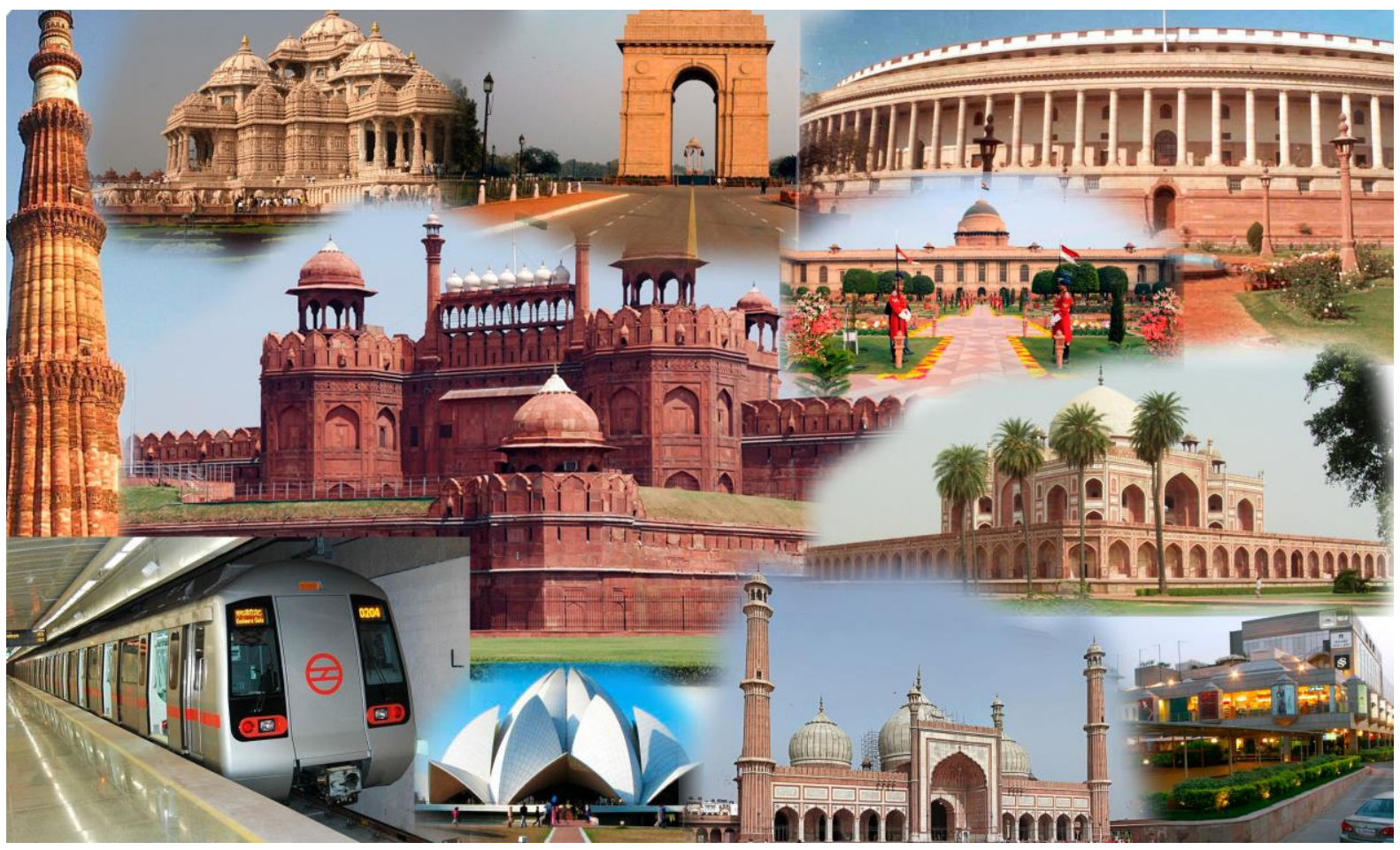

Figure 1. Delhi: Different Architectural Monuments in different style forming an Image of the City. Source: (Tripbeam, 2015)

These healthy urban places are created consciously and cannot be a result of an afterthought. As said by a famous urbanist Dan Bertolet, people in these urban areas should feel connectedness to the physical city and the people in it, as cities have the power to bring people together. Due to socio-economic structure and interconnectedness of ideas and shared experiences, cities become more vibrant in their functioning. The different functions of the city include public places such as parks and playgrounds, libraries, community centres and schools, and they are important hearts of civic life. Other than this, people are benefitted from a wide range of designs such as attractive sidewalks, bringing shoppers to main streets, landscaping trees that beautify the area, as well as improve air quality and water quality, and a plaza, making an enjoyable walk in the neighbourhood, building a social bond, and properly allocated investments bringing tangible and intangible returns (Adams, \& Tiesdell, 2012). Having said that, as cities are a mark of human civilization, urban spaces need to be compact in size, that does not mean small in size and should be well integrated with the countryside (ROGATKA, \& RIBEIRO, 2015: 129p). As Delhi is a capital of India, and hence crafted as a global city, it is open for people outside the boundaries of the nation. Economic inclusion is possible in places such as shopping malls, spas, restaurants and call centres which are stripped off from distinct national signifiers, and citizens in these areas live an exceptional lifestyle (McDuie-Ra, 2012). However, middle class communities have become part of the masterplan with community development programmes and their representation as Resident Welfare Associations (RWA) having legitimate claim to govern themselves (HULL, 2011).

\section{Literature review}

In the initial stages of the relationship between people and urban places, it all began as a negative characterisation of the industrial cities of late 19th century and early 20th century, lacking close face to face interactions unlike the traditional towns. These industrial cities were portrayed as dystopic and crowded hubs by scholars and novelists, always confronted by seemingly powerless individuals (Sen, Silverman, 2014). The city is divided in two levels, the first level is our close families and neighbourhoods, and second level is the city itself. These different levels are further housed into permanent structures, through 
economic organisation and publicly regulated institutions, within limited urban areas. Furthermore, the physical means of the urban area are fixed site, durable shelter, facility for assembly, interchange and storage, and the social means include division of labour embarking on cultural processes. The resultant city then, is a complete sense of a geographic plexus, an economic organisation, an institutional process, a theatre of social action, and an aesthetic symbol of collective unity. The different actors of the city play an active role within conflicting groups and events (Mumford, 2016).

Currently, the communities thus formed strictly deviate from 20th century modernism, with segregated land-use, and disconnected tower blocks, unlike were envisioned by architects like Le Corbusier. Streets now are more user friendly, and are places where people interact, children play, shoppers browse storefronts, and sidewalk vendors sell goods, unlike traffic machines. These are the places where there is a small, human scaled development with shared spaces promoted by acclaimed scholars and practitioners such as Jane Jacob (Cervero, Guerra, \& Al, 2017). Therefore, places denote a material world that are not only limited by physical boundaries, but also temporal and socially constructed boundaries. Martin Heidegger laid the foundation for the term 'placemaking', with his notion of 'Dasein' (Being in the world). This simply means that we cannot exist without our surrounding world, but also the world cannot exist without people in it. In other words, it is through our conscious actions and interactions that the physical world is brought into existence, and has a mutually constructive relationship with the physical world being part of the experience of human inhabitant, and its meaning is dependent on socio-economic and political context (Sen, Silverman, 2014).

Since the year 2000, Delhi has witnessed a construction and demolition boom, and therefore we can see a growing interest of urban artists in the fabric of the city. The speed and quality of transformation thus achieved is ecological, gendered as well as class-based politics. As stated earlier in the paper that this interest is not coincidental, and the artists may have different backgrounds, biographies and aspirations. Delhi is a subject of criticism for many environmentalists and planners, however, for some artists the marginalised layers of nature, culture, social and history are important to see in the future. For others, it is addressing the issue of habitat such as land grabbing, social inequalities and exclusion. These artists have an aspiration to research the glamourous surface of the city, and further dig deeper into layers of alternative habitat (BROSIUS, 2016, 141p).

The diverse data distance from or intimately close such as farming of marigold flower beds, farmers and resettled auto pullers, the habitat of homeless industrial workers or nomadic sadhvis, is collected by the artists, activists and archivist, as it is with the case of Atul Bhalla's work. His work is deeply rooted in environmental issues and water resources in the city in the context of physical, historical, spiritual and political significance of Delhi's population. Another artist, Sheba Chhachhi reveals layers of material which include other qualities of the city such as the river Yamuna. She follows the skilful poetic and research-based participation to understand spatial and temporal facets of the city. The third artist, Gigi Scaria and he brings insights into social structures and hierarchies of the built environment. Like Bhalla and Chhachhi, Scaria creates both distant and intimately close ways in which a world class collection of narratives and strategies can be challenged by everyday world (BROSIUS, 2016, 141 p.).

According to Cresswell, Urban places are the result of recording of activities in the built environment in the neighbourhood planning of cities (Fainstein, \& DeFilippis, 2016). Recently, within these neighbourhoods there is quite a bit of control of citizens with the public participation process being adopted in a more stringent way, and there are more opportunities for them to make their own contribution. Such kind of community participation avoids conflicts between planners, public officials, community organizers and leaders to make a community design decision. Such community participation is in the form of placemaking workshops, focusing on limited geographic space, a public square, a park, or a housing development, encouraging creative thinking. While others participate with information and options of resource allocation, land-use, or public transport. The information to citizens is presented in a digital format such as GIS and CAD, which makes them understand challenges of land-use in a simple manner. A common approach 
adopted in these community meetings is that they treat participants like adults, and a sense of being heard, by valuing their ideas (Nabatchi, \& Leighninger, 2015).

\section{Methodology}

In this research qualitative research methodology is used, with inductive reasoning from specific to general. We have used an example of a global city, 'Delhi' to generalise the concept of placemaking, and how local actors such as bureaucrats and stakeholders contribute to the discourse. In this research 'discourse analysis' method is used, in analysing the relationship of people in the making of urban places. The focus group for the research are the internal stakeholders like government, developers, planners and external stakeholders such as people in general. To answer the research question, how efficient, progressive and adaptive the systems are, in a continuously moving timeline, and how various actors in the system act in a given situation, a review of literature is conducted with a descriptive research design. There are two main challenges that are observed in placemaking and they are: 1 . What constitutes a good design 2. Delivering good design engaging with real estate processes, particularly through land-use plans. This paper puts emphasis on these challenges and further analyses the role of good design in the real estate development process in building an image of the city. The limitations of the paper include a smaller number of literature available for this topic, and it does not give a clear picture of the layers of the social strata. However, it develops into an interesting narrative about place making in the city of Delhi.

\section{Research Findings}

According to the discourse analysis of the literature review and the text, the relationship between people and urban places is derived, and is as follows: As a global city, Delhi, goes through an evolutionary process of planning, and it is a collective result of complex bureaucratic procedures, political ideologies, local and global economies and multicultural society. Some planners only focus on some specialised areas such as transportation planning, environment planning, real estate development, heritage and conservation etc. They use various data collection methods to collect data and evidence before preparing the plan. They also research, design, and develop programs; lead public processes; affect social change; perform technical analysis; manage; and educate. Planners help the community and its various groups to identify their goals and prepare strategies to implement the plan by enforcing it in coordination with many groups of people. Planners need to address growing concerns regarding sustainable communities. These concerns are satisfied with the help of plans that can take a variety of forms including policy recommendations, community action plans, comprehensive plans, neighbourhood plans, regulatory and incentive strategies, or historic preservation plans. Other examples of plans include redevelopment plans, smart growth strategies, economic development strategic plans, site plans, and disaster preparedness plans etc. (APA, 2015). Amongst these, relationships between people and urban places are highly influenced by the real estate development process which is described below.

The debate about what constitutes a good design is seen from the perspective of successful developers and architects in the real estate project. For a developer, a good design is one that offers a building that is not only a good affordable housing option but also one that is cost effective to own, operate and maintain over a long period of time. This requires a strong vision, leadership and attention to detail. However, the question is whether other stakeholders of the real estate project, such as architects, planners, the public at large and potential buyers and tenants do think the same way? And whether this changes according to the location in which they exist. To answer these questions let us see real estate in a holistic way. The term real estate means different things to different people. For most of the general public, it means the physical homes that we live in and the commercial office spaces where they work. For a planner, it is a way in which the economic goals are achieved through comprehensive planning such as social goals, business growth, job creation and housing development. They also may influence the geographic direction of development, for instance, encouraging high density mixed-use development around transit stations. For elected 
politicians it may mean, development as means to encourage investments that are in line with policies, plans and desires of their constituents, and expand on the tax base of an urban area. For an architect, it may mean a project that will generate fees and can lead to repeat business, exploring their own aesthetic ideas. For an investor it is a better option to low-risk investments such as share market, and lastly for a developer it is just a product that will be sold in the market (Brown, 2015).

Planning neighbourhoods and cities start with a land-use map which is published for 20 to 25 years. Landuse maps is a comprehensive land management system (Enemark, Hvingel, \& Galland, 2014, 343p) that caters to the primary and secondary needs of the citizens, facilitating investment opportunities in certain strategically important locations on one hand, and puts restrictions on land which are of heritage value both in terms of the natural and built environment on the other (Figure 2). The transport corridors, industrial development and other social institutions such as universities, hospitals, post offices, fire stations become an integral part of the land-use map. These zones are identified on the map as per spatial planning strategies i.e., proximity of land-use based on their function. Land use maps are then supplemented with planning policies that enable people to take advantage of the land in question. Thus, a business cycle is complete, and cities start functioning. Furthermore, suggestions and objections are invited from the citizens and amendments are made for a reasonable claim (Figure 2). To make day to day business more ethical, credible and accountable, several compliances are made mandatory to establish order and security.
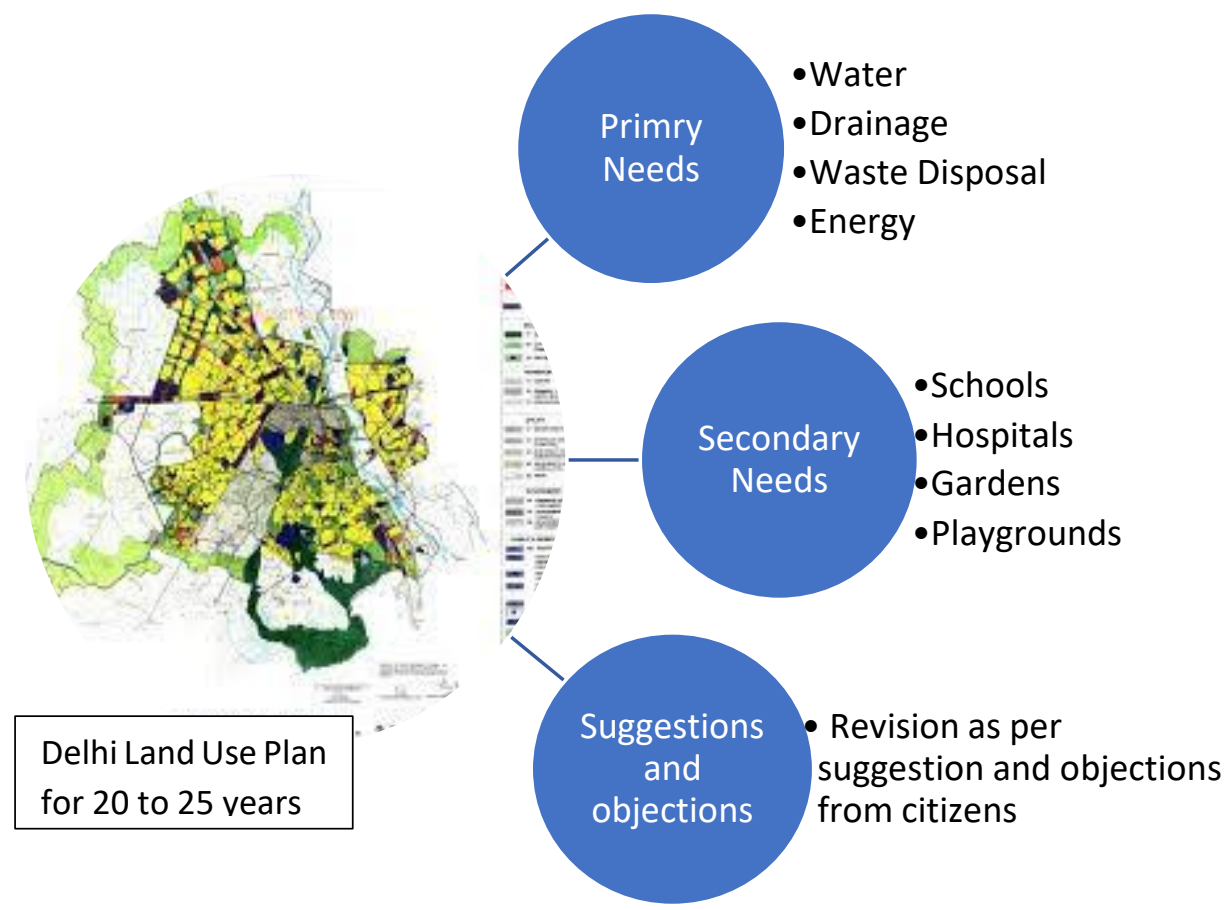

Figure 2: Land Use Plan and Citizen Needs

\section{Conclusion}

Socially sustainable cities are the result of the transformation of deprived urban areas, and it is also instrumental in attracting new investments to cities (KRIŽNIK, 2018, 83p). For South Asian cities like Delhi, they must transform themselves into productive and liveable places by not only focusing on rapid expansion of their peripheries, but also addressing challenges of their city cores. These are commonly observed places which are associated with congestion forces including clogged streets, polluted air, unaffordable land and the prevalence of slums. It is of national importance, how these places in the cities are connected spatially 
to other towns and cities. Relationships between people and these places are a result of appropriate and effective policy design and regulations but can be daunting if there is a defective governance and finance deficit. The market forces do not address the issues of externalities such as public infrastructure, which is only possible through government intervention. Furthermore, policy failure can hinder the development and therefore, it is essential that a sound urban government, capable institutions, and good leadership is in place to build capacity for good policy making and effective spatial planning. Such cities can be transformed through integrated design in spatial planning, shaping the urban form by a variety of land-use patterns and vibrant neighbourhoods. These approaches require attention to details such as local area development plans, streetscape improvement, public space provision, urban design, good connectivity and place making. The implementation of these details allows greater dynamism and flexibility that can respond to short term needs, and long-term needs in spatial planning development (Ellis, \& Roberts, 2015). The built environment of a city like Delhi invokes soft power which should involve cultural values and policies that become symbolic, iconographic, placemaking, and can be expressed as cultural, and poetic identity of the nation state (Wildsmith, 2018, 85 p.). In such a venture, Delhi must adopt new architectural styles and movements expressing an image of the city as the capital of India.

\section{References}

Adams, D., \& Tiesdell, S. (2012). Shaping places: Urban planning, design and development [online]. Available from: ProQuest Ebook Central https://ebookcentral.proquest.com (Accessed: 4 July 2021).

American Planning Association (2015) What is planning? [online]. Chicago, Washington D C: American Planning Association. Available from: https://www.planning.org/aboutplanning/whatisplanning.htm (Accessed 16 July 2021)

Assetyogi (2021). Delhi master plan 2021 - Map and Highlights [online Image]. Available from: https://assetyogi.com/delhi-master-plan/ (Accessed 11 September 2021).

Bain, L., Gray, B., \& Rodgers, D. (2012). Living streets: Strategies for crafting public space [online]. Available from: ProQuest Ebook Central https://ebookcentral.proquest.com (Accessed 5 July 2021).

BROSIUS, C. (2016). READING THE CITY THROUGH ART. India International Centre Quarterly, 43(3/4), 139158 [online]. Available from: http://www.jstor.org/stable/26317321 (Accessed 11 July 2021)

Brown, P. H. (2015). How real estate developers think: Design, profits, and community [online]. Available From: ProQuest Ebook Central https://ebookcentral.proquest.com (Accessed 14 July 2021)

Cervero, R., Guerra, E., \& Al, S. (2017). Beyond mobility: Planning cities for people and places [online]. Available from: https://ebookcentral.proquest.com/lib/britishcouncilonline-ebooks/reader.action?do $c \mid D=5602383 \& p p g=9$ (Accessed 4 July 2021)

Ellis, P., \& Roberts, M. (2015). Leveraging urbanization in south asia : Managing spatial transformation for prosperity and livability [online]. Available from: ProQuest Ebook Central https://ebookcen tral.proquest.com (Accessed 6 July 2021)

Enemark, S., Hvingel, L., \& Galland, D. (2014). Land administration, planning and human rights. Planning Theory, 13(4), 331-348 [online]. Available from: http://www.jstor.org/stable/26098687 (Accessed 19 July 2021)

Fainstein, S. S., \& DeFilippis, J. (Eds.). (2016). Readings in planning theory [online]. Available from: ProQuest Ebook Central https://ebookcentral.proquest.com (Accessed 18 July 2021) 
HULL, M. (2011). Communities of Place, Not Kind: American Technologies of Neighborhood in Postcolonial Delhi. Comparative Studies in Society and History, 53(4), 757-790 [online]. Available from: http://www.jstor.org/stable/41241864

KRIŽNIK, B. (2018). Transformation of deprived urban areas and social sustainability: A comparative study of urban regeneration and urban redevelopment in Barcelona and Seoul. Urbanilzziv, 29(1), 83-95 [online]. Available from: http://www.jstor.org/stable/26446685 (Accessed 20 July 2021).

MARLEWICZ, H. (2016). HETEROTOPIAN CITY: KHUSHWANT SINGH AND HIS DELHI: A NOVEL. Politeja, (40),159-176 [online]. Available from: http://www.jstor.org/stable/24920201 (Accessed 11 July 2021).

McDuie-Ra, D. (2012). Coming to Delhi. In Northeast Migrants in Delhi: Race, Refuge and Retail (pp. 61-86). Amsterdam: Amsterdam University Press. [online], Available from http://www.jstor.org/sta ble/j.ctt46mv07.7 (Accessed 11 July 2021).

Mumford, L. (2016). The culture of cities [online]. Available from: https://ebookcentral.proquest.com (Accessed 4 July 2021).

Nabatchi, T., \& Leighninger, M. (2015). Public participation for 21st century democracy [online]. Available from: ProQuest Ebook Central https://ebookcentral.proquest.com (Accessed 18 July 2021)

ROGATKA, K., \& RIBEIRO, R. (2015). A compact city and its social perception: A case study. Urbani Izziv, 26(1), 121-131 [online]. Available from: http://www.jstor.org/stable/24920969 (Accessed 20 July 2021)

Sen, A., \& Silverman, L. (Eds.). (2014). Making place: Space and embodiment in the city [online]. Available From: ProQuest Ebook Central https://ebookcentral-proquest-com.library.britishcouncil.org.in:444 (Ac cessed 4 July 2021)

Tiesdell, S., \& Adams, D. (2011). Urban design in the real estate development process [online]. Available from: ProQuest Ebook Central https://ebookcentral.proquest.com (Accessed 6 July 2021)

Tripbeam (2015). Top Attractive Places to Visit in Delhi [online Image]. Available from: https://www.tripbeam.com/blog/top-attractive-places-to-visit-in-delhi (Accessed 19 July 2021)

Wildsmith, D. (2018). CAPITAL CITIES: SHAPING POLITICS, POETICS AND PLACE. Traditional Dwellings and Settlements Review, 30(1), 85-85 [online]. Available from: https://www.jstor.org/stable/26877478 (Accessed 20 July 2021) 